\title{
Energy Efficiency Policy and Energy Management at Enterprises
}

\author{
Baizholova Raissa and Sadykova Perizat
}

\begin{abstract}
Article refers to one of the fastest growing trends in innovation - energy efficiency. The study paper is based on analysis of the level of energy efficiency of the Common Economic Space (CES) with the most common indicators of energy efficiency that author comes to conclusion of application of the experience of the developed countries for energy -saving and energy efficiency. Industry of Kazakhstan, including energy sector, uses the huge amount of energy and causes significant pollution on environment. The author articulates the general recommendation on establishment and implementation of energy management systems on the enterprises.
\end{abstract}

Index Terms-Energy efficiency, energy management, energy saving, innovation.

\section{INTRODUCTION}

One of the fastest growing trends in the field of innovations is energy efficiency, which received much attention. To date, the issue of energy efficiency is very topical, since these areas can make the greatest contribution to the sustainable development of the country by reducing the energy intensity of the economy and contribute to enhancing the competitiveness of goods and services. The global economic crisis has made this topic very important worldwide. The implementation of energy efficiency policies laid serious reserves to counter the effects of the crisis and economic modernization.

According to the world leading economic centers in the XXI century the solution to the problem of saving different resources and its impact on national economies will be a key factor in improving the competitiveness of output and budget savings. Today, energy performance issues cannot be considered separately from economic activities and, on the contrary, one cannot talk about economic development without saving natural and other resources.

That's why the energy policy aimed at energy conservation is a priority component of socio-economic development of the Republic of Kazakhstan.

JEL Classification: O10, O13, O31.

\section{LITERATURE REVIEW}

Implementation problems on energy efficiency policy devoted on the studies of I. Bergman, M. Porter, M. Fezera, D. Hasbi, M.Enrait and others. For the last years made researches on energy-saving management on B. P.

Manuscript received January 3, 2013; revised February 17, 2013.

The authors are with Eurasian National University named after L. N. Gumilyov, Kazakhstan (e-mail: baizholova_55@mail.ru, Perizat_st@mail.ru)
Meshalkin, S. A. Michailov, A. A. Balyanbina's studies [1], [2]. Also evaluation of energy-saving on regional level [3]. Energy system management [4].

G. R. Yarullina on own research defined instruments of efficient usage of energy recourses and other problems of energy saving on industrial enterprises [5].

\section{Designing Energy Saving Policy and Enhancing Energy Efficiency}

Designing energy saving policy and enhancing energy efficiency is a multifaceted process including a variety of stages - from setting priorities to the development and coordination of the policy, setting the targets. All these elements are essential for a comprehensive and sustainable policy on energy efficiency, which can be successfully implemented in practice.

The global experience of improving energy saving policy and enhancing energy efficiency shows that many developed countries have recognized energy efficiency to be a priority (Japan, Sweden, Norway and Finland).

The main condition for the success of any national energy efficiency strategy is a sound institutional and policy framework. This means that there is a strong public commitment to energy efficiency as embodied in the specific policy and framework ensuring the possibility of its practical implementation. Such countries implement the policy of energy conservation and energy efficiency. The following important processes of such a policy are common for all countries [6]:

1) Creating a strategic framework in the area of energy efficiency - the basis for energy saving policy.

2) Maintaining a legislative framework in the field of energy efficiency. So as the political system of energy saving functioned efficiently there is the need for clear legislation, policy and strategy.

3) Forming energy efficiency targets in the energy efficiency. Targets play the important role in motivating participants to take measures and serve as orientation in assessing the results. They can be set at any level - from the companies to the entire country. They may relate to energy saving, reduction of energy consumption and emissions of steam generators (SG).

4) Strengthening the institutional framework in the field of energy efficiency.

The analysis of the public policy on inter sectoral level showed that in terms of improving the energy efficiency policy the gap between the enlarged EU and the CIS countries remains tangible. And Kazakhstan is not the exception. Practical implementation of energy efficiency measures - is a difficult and controversial issue. Its solution requires political commitment, a comprehensive action plan, as well as human and financial resources.

The analysis suggests that for the full functioning of all 
these bases, it is necessary to expand the list of targets, both at the national and sectoral levels.

It was conducted the analysis of the level of energy efficiency of the Single Economic Space (SES) with the use of the most common indicators of energy efficiency.

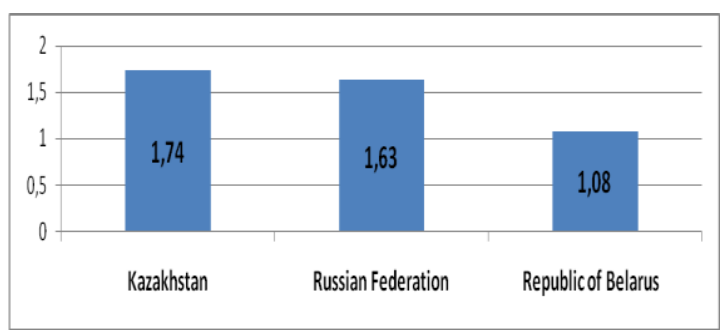

*according to IEA (http://www.iea.org/stats/index.asp)

Fig. 1. Dynamics of GDP power intensity (TPES/GDP) of the SES countries (TOE/USD thous.) in 2009

So, the current situation shows that the economy of Kazakhstan has the highest indicators of the GDP energy intensity on purchasing power parity, compared with that of Russia and Belarus. In 2009, the GDP energy consumption of Kazakhstan exceeded the energy intensity of Russia by 0.11 TOE / USD thous., and the power consumption of Belarus by 0.66 TOE / USD thous. (Fig. 1).

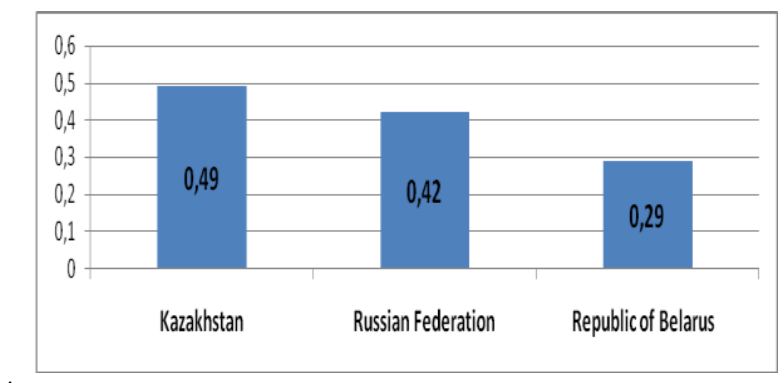

*according to IEA (http://www.iea.org/stats/index.asp)

Fig. 2. Dynamics of GDP energy ntensity on purchasing power parity(TPES/GDP (PPP)) of the SES countries(TOE/USD thous.) in 2009

The GDP of energy intensity on purchasing power parity of Kazakhstan exceeded the energy consumption of Russia by 0.07 TOE / USD thous., and the energy intensity of Belarus by 0.20 TOE / USD thous. (Fig. 2).

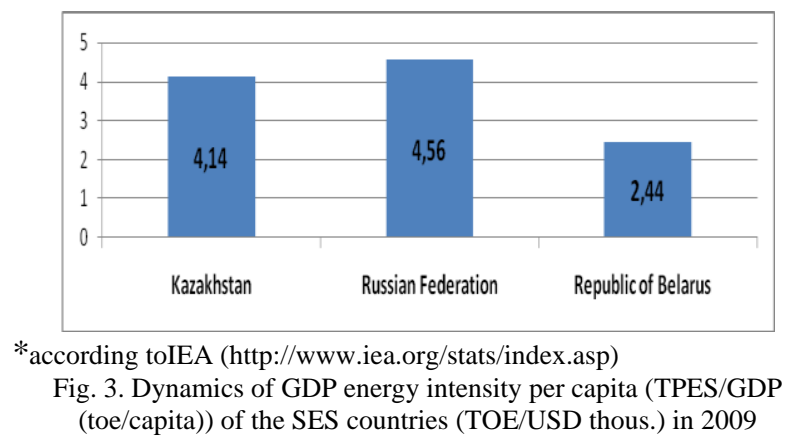

If we consider the indicator such as the GDP energy consumption per capita, it should be noted that Kazakhstan's energy intensity is slightly lower than in Russia -by 0.42 TOE / USD thous., but at the same time is higher than in Belarus by 1.7 TOE / USD thous. (Fig. $3)$.
To implement the policy in the area of improving at the cross-sectoral level it is required to develop mechanisms for the implementation of the state policy within each sector, which includes solution of a number of tasks.

As the illustrative description of the proposed approach to improve energy saving policy in a particular industry it was analyzed such a key sector as industry.

Kazakhstan industrial base is focused on heavy industry and processing of raw materials, requiring a significant amount of electricity. Industry of Kazakhstan, including the power sector consumes a lot of energy and causes significant environmental pollution. The share of industry (including power) falls to $72 \%$ of electricity consumed by the country. The share of ferrous and non-ferrous metals falls to $44.8 \%$ of the electricity consumption by the industry, the share of mining $-22.8 \%$ of the electricity consumption by the industry. In general, the share of industrial energy consumption of the total energy consumption in the country made $45 \%$. Energy consumption in the industry compared to 1992 has decreased by $55 \%$, but since 1999 there has been a steady increase in energy consumption in industry (from 1999 to 2009 the increase was $30 \%$ ) [7]. Based on that, we can conclude that the energy saving potential in the industry is high (it is estimated in tens of per cent of consumption volume), which is associated with the use of outdated technologies and equipment.

\section{MeThODOLOGY}

There are various methods of energy policy, energy saving and definition of energy management. Thus, V.G.Tarasovskiy, Technical Director of "Enterprise of the Group of "Town Center for Expertise" LLC - "Town Center for ExpertisePower", $\mathrm{PhD}$ in Technical Sciences, Associate Professor in his paper "Energy Management System. Difficulties in the Development and Implementation" considers the energy policy to be the official written declaration of interest in the expedient use and saving of fuel and energy resources, protection of the environment, accompanied by a list of formulated objectives, action plan for their achievement, providing necessary resources and a clear distribution of delegated authorities, duties and responsibilities. The author also considers the energy policy as one of the first and essential elements of energy efficiency. Some authors on energy-saving define that activities of efficiency as satisfactory usage of society on energy services [5].

In the article "Organization of energy management at the enterprise" by S.A.Sinitsyn - Chief of the laboratory for metrology and quality of electric power of the branch "Mosenergosbyt - Technical Center" and V.I.Babich - PhD in Technical Sciences, Director General of "Power Company "Joule", published in the scientific, technical, analytical and educational-methodical magazine: "Energy security and energy efficiency"\# 6, 2009, the concept of energy management is considered to be a synonym of energy consumption management. Through implementation of energy management one can obtain a more detailed picture of energy consumption, which will make it possible to assess the energy savings projects planned for realization at the enterprise.

Thomas Mort in the article: "Energy management process", published in the magazine "Strategic Planning for Energy and Environment", v.21.,\# 1, 2001, introduces the definition of 
energy management, according to which energy management - is structured methods used to achieve success in the reduction of energy consumption at the industrial enterprises.

In our glance energy-saving is the most important factor of advancing energy-efficiency, which achieved decreasing energy cost of enterprises. Energy management is one of the main element of management system in our research subject. Market relations, or rather competitive relationship in the limited markets of commodities shaped the direction of the management systems development - "cost management". The most common, applicable in various industrial processes resources (costs) have led to the detailed cost management systems by the type of resources. Such sections as "financial management" and "energy management" have been designed. "Energy management" is in the initial stage of development, therefore, requires the integrated approach to its study.

Energy management is a tool for the company's management, which provides continuous information on the energy distribution, consumption and use in the company. Thus, the energy management system is the effective measure for increasing the efficiency of the enterprise, which requires a systematic approach to using it.

Implementation of the best practice of energy management system can make a contribution to the energy efficiency of the enterprise.

Only by a complex of organizational measures it is possible to achieve a significant increase in the efficiency of fuel and energy resources utilization.

\section{RESUlTS}

According to the international practice the public policy of energy saving should be aimed at building and strengthening the following basis:

1) Strategic framework. In 1996 it was elaborated and adopted by the Government of the Republic of Kazakhstan a special state program for energy saving. However, this Program does not provide a consistent implementation of the energy saving potential throughout the energy cycle from production to consumption. In the meantime, the Comprehensive plan for energy saving was designed. The main objective is to develop a set of legislative, organizational, scientific, technical and coordinated with the state budget economic and financial measures [8].

2) Legislative framework. The main instrument of the state policy is the Law "On energy saving and energy efficiency"[9].

3) Targets. The main indicators are as follows:

Reduction in energy intensity of the gross domestic product of the Republic of Kazakhstan from 2008 level by at least $10 \%$ and $25 \%$ to 2015 and 2020, respectively, through the effective use of fuel and energy resources [10]. It should be noted that there are different problems, but there are no specific quantitative indicators as a whole for energy efficiency.

1) Institutional framework. Ministry of Industry and New Technologies is responsible for the implementation of state policy in the field of energy saving.

Another important step is the formation of a number of tools and comprehensive measures to achieve energy savings in the industry.

1) Collection of high quality data on energy efficiency in industry [11]. Without accurate data it is difficult to direct and develop the appropriate energy efficiency measures for such an important sector in terms of energy consumption.

2) Introduction of standards of minimum energy characteristics for the equipment [12]. The average energy efficiency of new equipment in the countries applying such requirements is much higher than in countries that do not have such requirements - thus, this policy instrument proved to be practicable and costeffective for energy saving. Thus, the government should consider the introduction of mandatory minimum energy efficiency standards for equipment based on the best international practice.

3) Energy management at large industrial enterprises. The use of this instrument is the most effective in order to improve energy efficiency. In other words, it is required to implement the energy management system at the enterprises. The effectiveness of the latter instrument, of course, is high, so it is necessary to reveal it in more detail.

The energy management system - a management system based on the standardized measurement and verification, providing a mode of operation in which it is consumed only the amount of energy needed to produce goods or services. Energy management is a tool for the company's management, which provides continuous information on the energy distribution, consumption and the use of energy both for production purposes as well as for other non-productive purposes. Thus, the energy management system is an effective tool of increasing the efficiency of the enterprise.

The main goal of energy management is to reduce the costs of the enterprise for the output of products or to provide services by reducing the cost for energy and other resources. At that, energy management must be the efficient (performing) and stable operating system that provides a solution to the main goal [13].

Obvious is the fact that a breach of relations between certain units (stages) of the process of functioning of energy management as a system leads to the cessation of its operation, i.e. to the non-fulfillment of the main task - reducing energy costs and increasing efficiency.

In order to achieve the main goal of energy management it is necessary to solve the following problems [14]:

- creation of a complete picture of energy consumption at the enterprise;

- creation of the accounting and control system for energy consumption;

- regular analysis of energy consumption; 
- development and implementation of energy saving measures.

\section{CONCLUSION AND IMPLICATIONS}

Thus, it is possible to make general recommendations on the creation and implementation of energy management systems at the enterprise:

- development of energy policy and strategy, buildup and implementation of the policy document of a company in the area of energy saving;

- determination of the energy management service structure and its quantitative composition. Development and approval of regulations on energy management system at the enterprise;

- conduction of a comprehensive energy audit, formation of the fuel and energy balance of the enterprise (determination of the energy basis of the company);

- creation of the employee incentive program for enhancing energy efficiency and energy saving;

- providing staff development in the field of energy conservation; certification of officials according to ISO 50001 standard along with ISO 9001 and ISO 14001standards;

- introduction of technological accounting of energy resources, monitoring of key indicators of energy efficiency of the enterprise.

The experience of developed countries shows that only by a complex of organizational measures it is possible to achieve a significant increase in the efficiency of fuel and energy resources utilization. This effect can be up to 5$10 \%$, and sometimes more of the total consumption of fuel and energy resources [15].

\section{REFERENCES}

[1] S. A. Michailov and A. A. Balyabina. "Advancing competitiveness of enterprises of region on the base energy saving management," in Proc. Competition and competitiveness. Organization of industry competitiveness production: VII international conference, Novocherkassk, pp. 105-107. 2009.

[2] S. A. Michailov and A. A. Balyabina, "Institutional changes in economy, right and education in modern Russian society," Novokuznets: Sibirskii branch MIEP, pp. 184-185., 2009.

[3] B. P. Meshalkin, "Evolution of potential energy-saving in regions," Management in Russia in abroad, no. 3. pp. 53-59, 2010.

[4] T. E. T. Markov, Scientific-methodological principle of energy audit and energy management, Nauka. pp. 537, 2005,

[5] G. R. Yarullina, Managing energy saving on industrial enterprises, 2003.

[6] International Energy Agency in support of the Action Plan of "Big8", Guidelines for Energy Policy, pp. 11-13, 2009.

[7] Energy Charter Protocol on Energy Efficiency and Related Environmental Aspects, Regular Review of Energy Efficiency Policies in Kazakhstan, pp. 26-30, 2006.
[8] Comprehensive Plan for Improving the Energy Performance of the Republic of Kazakhstan for 2012 - 2015, approved by the Decree of the Government, no. 1404, November 30, 2011.

[9] The Law On Energy Saving and Energy Efficiency of the Republic of Kazakhstan, no. 541-IV, 2012.

[10] Decree of the President of Kazakhstan Nursultan Nazarbayev, no. 922, 2010

[11] Energy Charter Secretariat: Policy Developments and Challenges in Delivering Energy Efficiency, September, pp. 56, 59, 2007.

[12] Energy Charter Secretariat: Policies that Work: Introducing Energy Efficiency Standards and Labels for Appliances and Equipment, pp. 13, 2009.

[13] Progress of Energy Performance in the "Big8" countries: Focus on Russia, International Energy Agency, pp. 21, 2010.

[14] Comprehensive Assessment of the Management and Technological Development and Energy Performance of the Subsidiaries of JSC "SWF "Samruk-Kazyna, Analyst Report, Astana, November, pp. 13, 14, 2011.

[15] Energy Charter Secretariat, In-depth Review of Policies andPrograms in the Field of Energy Efficiency, pp. 55, 2008.

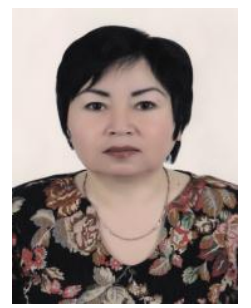

Raissa Baizholova was born at 25th January of 1955 in Kyzulorda region of Kazakhstan. In 1972 year admitted to E.A. Buketova Karaganda University on specialty "Economics and planning materiel technical providing". After graduation has been working on education system for 30 years. In 1999 defended candidate of economics, and in 2002 became docent. In 2010 year defended doctor of economics. For 2001-2005 worked as head of department and "Management and marketing". At this moment working as a professor and head of Economics department, at L.N.Gumilev Eurasian National university.

Baizholova Raissa has participated actively on preparation recommendation methodology of credit technology. Baizholova Raissa has 32 methodological works, more than 80 articles which is including 3 monographs. List of monographs: "Government regulation of national labor market under globalization", Astana, KazGJU, 2010. "Globalisation and national market: relation and employment", ENU, 2012 and "Functions of financial institutes and financial sector in market economy", ENU, 2012. Prof. Baizholova Raissa won competition "Best university teacher".

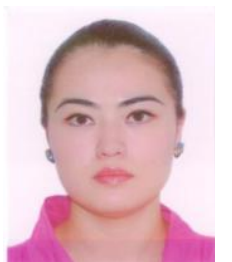

Perizat Sadykova was born on 26th August of 1987 in Karaganda region of Kazakhstan. In 1972 year admitted to Eurasian National University after L.N. Gumilyov on specialty "Finance". After that she graduated Moscow State University after M.V. Lomonossov. She has an academic degree as a Master of Economics. Now sahe is a $\mathrm{PhD}$ candidate Eurasian National University after L. N. Gumilyov. At this moment working as a manager of the Department of Innovation Policy JCS "NWF"Samruk-Kazyna".

Perizat Sadykova 1 monograph: "Functions of financial institutes and financial sector in market economy", ENU, 2012 and many articles which is including: "The priorities and directions of scientific and technological development of the Republic of Kazakhstan" published in the scientific journal "Herald" KazEU after T.Ryskulov, 2011, "Global Trends and selection of scientific and technological trends in the Republic of Kazakhstan" and published in the proceedings of the VIII th International CONFERENCE. - POLAND: SCIENCE AND STUDIO, 2012. 